\title{
COMPARATIVE STUDY ON INDIVIDUAL AND COMBINED EFFECTS OF ZIRCONIUM DIOXIDE AND GRAPHITE REINFORCEMENTS ON MECHANICAL PROPERTIES OF AL 6061 COMPOSITES
}

\author{
Harish B R ${ }^{1}$, A K Shaik Dawood ${ }^{2}$, Nagabhushan ${ }^{3}$, Santosh Pimpale ${ }^{3}$, C V Raja Reddy ${ }^{4}$ \\ ${ }^{1}$ Research scholar, Research Centre, Karpagam University, Pollachi Main Road,Eachanari Post, Eachanari, \\ Coimbatore, Tamil Nadu, India \\ ${ }^{2}$ College of Engineering, King Khalid University, Abha, Saudi Arabia. \\ ${ }^{3}$ Research scholar, Mechanical Engineering Department, The oxford college of Engineering, Bangalore, Karnataka, \\ India \\ ${ }^{4}$ Associate Professor, Department of ME, T. John Institute of Technology, Bengaluru, Karnataka, India
}

\begin{abstract}
Aluminium matrix composites (AMCs) are commonly used as break pad materials for engineering applications because of the unique characteristics it possess which fit the necessary requirements. In this work, individual and combined effects of zirconium dioxide and graphite reinforcements on mechanical properties of Al 6061 composites were investigated. The matrix combination with Al6061 as base was varied in terms of weight percentages of zirconium dioxide (2.5\%, 5\% and $7.5 \%)$ and graphite (1\% and $3 \%)$ separately and hybrid composite with zirconium dioxide( 1 to 6\%) and graphite(1\%) producing specific test specimens suitable to specific test conditions. Experiments, such as, micro-structure, micro-hardness, tensile test, and izod impact test which determine mechanical behaviours were conducted both on the base metal (Al 6061) as well as on the composites. These results provide insight view of effects of reinforcements on particulate reinforced composites,
\end{abstract}

Keywords: Stir Casting, Aluminum 6061, Zirconium Dioxide, Tension Test, Izod Inpact Test, Hardness Test.

\section{INTRODUCTION}

Al matrix composites have been used in all fields of engineering and are expected to replace most of the traditional material alloys in the long run. Al matrix composites may be manipulated to achieve various mechanical properties. In this regard various grades of $\mathrm{Al}$ are developed to fit into the application requirements [1]. Al based metal matrix may be formed by either continuous reinforcements or discontinuous reinforcements. Discontinuous reinforced Al matrix composites have attracted tremendously because of isotropic properties that it possesses. Isotropic properties of discontinuous reinforced $\mathrm{Al}$ metal matrix composite are higher than its unreinforced counterparts. Numerous researches have been carried out on $\mathrm{Al}$ matrix composites of which, few are on hybrid $\mathrm{Al}$ metal matrix composites.

Detailed study was conducted in this regard by understanding the importance of mechanical properties and machining behaviours. Literature study has revealed that the hardness of Al metal matrix composites increase by increase of ceramic particles reinforcements. Hybrid composites have possessed high hardness and tensile strength then unreinforced counterparts. Inclusion of reinforcements has shown increase in mechanical properties like hardness, tensile strength, compressive strength and ultimate tensile strength of Al alloys[2-9]. Machinability of Al based hybrid metal matrix composites has been an interesting area for many researchers. Operations like Turing, drilling, milling, shaping, grinding etc. and some of the non-conventional machining processes are in use for manufacturing metal matrix composites. It has been found that in case of processing hybrid metal matrix composites, higher cutting speed give superior surface finish and vice versa. If higher finish has to be established with minimum cutting speed then low depth of cut and minimum feed are the ideal requirements. It is also seen that the machining capability of a composite and cutting tool life increases due to inclusion of solid lubricants [10-12].

\section{EXPERIMENTAL}

\subsection{Material Selection}

At present $\mathrm{Al} 6000$ series alloys are very frequently used matrix materials for producing hybrid composites for heavy load wear applications. High percentage of elongation and high hardness of Al 6000 series materials has enabled its usage for most of the industrial applications [12]. In this study Al6061was used as the matrix material because of the superior hardness it possesses over other aluminium alloys. $\mathrm{Al} 6061$ was procured at a grain size of 100 microns. The chemical composition of the material is as detailed in the below table 1 . 
Table1. Chemical composition of Aluminium 6061 (Wt.\%).

\begin{tabular}{|c|c|c|c|c|c|c|c|c|}
\hline Element & $\mathrm{Cr}$ & $\mathrm{Fe}$ & $\mathrm{Mg}$ & $\mathrm{Mn}$ & $\mathrm{Si}$ & $\mathrm{Zn}$ & $\mathrm{Ti}$ & $\mathrm{Al}$ \\
\hline $\begin{array}{c}\text { Amount } \\
\text { (Wt.\%) }\end{array}$ & 0.3 & 0.5 & 1.2 & 0.15 & 0.6 & 0.15 & 0.1 & $\mathrm{Bal}$ \\
\hline
\end{tabular}

Zirconium dioxide $\left(\mathrm{ZrO}_{2}\right)$ is used as one of the reinforcement's owing to its higher hardness, melting point, and oxidizing properties it possess. $\mathrm{ZrO}_{2}$ of 100 microns grain size was used for the composite preparations. Inclusion of $\mathrm{ZrO}_{2}$ was varied in various percentages for the analysis. It is available in nature as mineral zircon. Because of the good oxidizing properties it possess, $\mathrm{ZrO}_{2}$ enables good corrosion resistance. $\mathrm{ZrO}_{2}$ was prepared in the form of powder at a grain size of 100 microns. Table 2 represents the constituents of $\mathrm{ZrO}_{2}$.

Table 2. Constituents of $\mathrm{ZrO}_{2}$

\begin{tabular}{|l|c|c|c|c|c|}
\hline Element & $\mathrm{ZrO}_{2}$ & $\mathrm{SiO}_{2}$ & $\mathrm{TiO}_{2}$ & $\mathrm{Fe}_{2} \mathrm{O}_{3}$ & Other \\
\hline $\begin{array}{l}\text { Amount } \\
\text { (Wt.\%) }\end{array}$ & 99.5 & 0.1 & 0.007 & 0.002 & 0.39 \\
\hline
\end{tabular}

Graphite will be used as soft reinforcement on account of its low coefficient of friction, excellent thermal conductivity and corrosion resistance. Also, Graphite will act as a solid lubricant for frictional applications. Preparing composites with built in solid lubricating characteristics is of major importance for antifriction applications. The formation of third-body films comprised of solid lubrication layers or particulate reinforcement of solid lubricants plays a vital role during practical application of the composite. Graphite prepared in the form of powder at a grain size of 100 microns.

\subsection{Experimental Setup}

Stir casting process was used to prepare composite. In the stir casting process, Electrical resistance furnace as shown in figure 1 is used to melt the matrix metal at a temperature of $850^{\circ} \mathrm{C}$, the crucible inside the furnace is covered by refractory composite from top to minimize the heat loss. Meanwhile the dies or moulds are sealed between the joints and are pre-heated in pre-heating furnace to remove the moisture and minimize the solidification rate of molten metal the dies are pre-heated at a temperature of $350^{\circ} \mathrm{C}$. Reinforcements $\mathrm{ZrO}_{2}$ and Graphite are taken in weight $\%$ and pre-heated at $350^{\circ} \mathrm{C}$ for remove moisture content. Hexacholoroethane commercially known as degassing tablet is added to remove slag from the molten aluminium. Reinforcements were added and the mechanical stirrer with a speed of $600 \mathrm{rpm}$ was introduced. The stirring operation was carried out for five minutes, then the reinforced matrix or base was heated for few more minutes. Crucible with molten metal is taken out of the furnace and poured into the pre-heated dies. Steady pouring rate was maintained to obtain uniform directional solidification. After the pouring is completed, casted composite was allowed for complete solidification in still air.

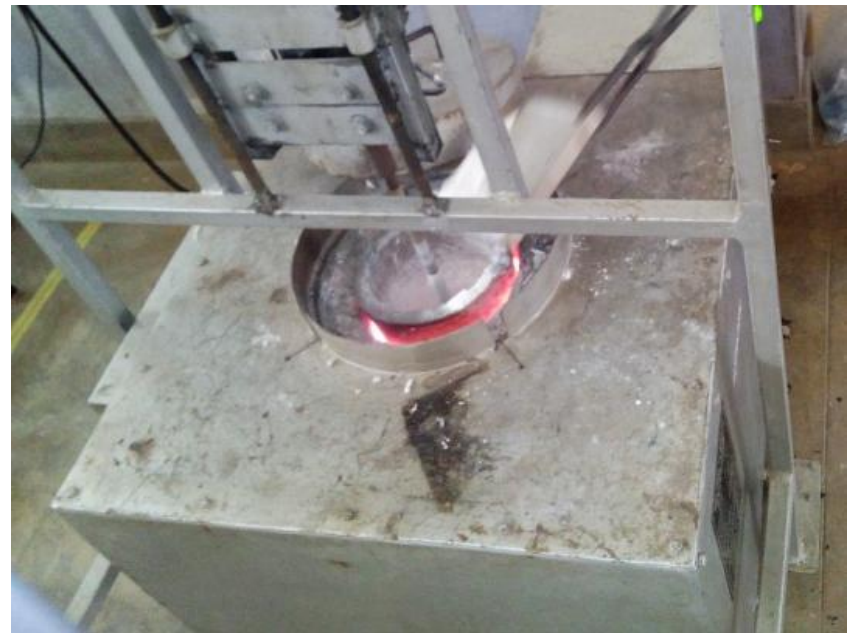

Figure 1. Stir casting experimental setup

\section{EXPERIMENTATION AND RESULTS}

\subsection{Microstructure Study:}

Microstructure test were carried out on each of the 11 composites prepared and also on the base metal alloy (AL6061). Microstructure tests are usually conducted on composites to analyze the distributions pattern of the reinforcements in matrix material. In this study, microstructure tests were carried out to analyze the distribution pattern of $\mathrm{ZrO}_{2}$ and Graphite reinforcements in the matrix material Al6061. In this study a standard microstructure test method of IS: 7739 PART V - 1976 (RA 2007) was used to carry out the microstructure test. 600,800 and 1000 grit size, silicon carbide papers were used to polish the surface of the specimen. Mirror finish was obtained by fine polishing using a diamond paste. Standard specimens of diameter $15 \mathrm{~mm}$ and length $15 \mathrm{~mm}$ were prepared for studying the microstructure of the surfaces for each hybrid composition.

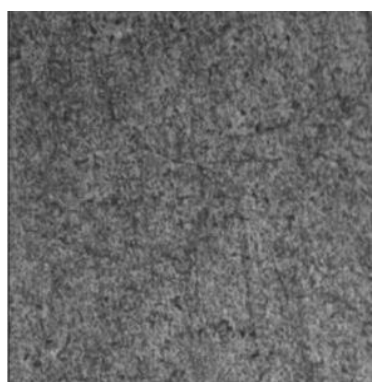

(a) Al 6061

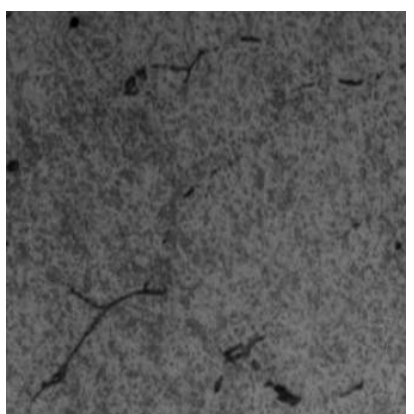

(c) $\mathrm{Al} 6061+2 \% \mathrm{Gr}$

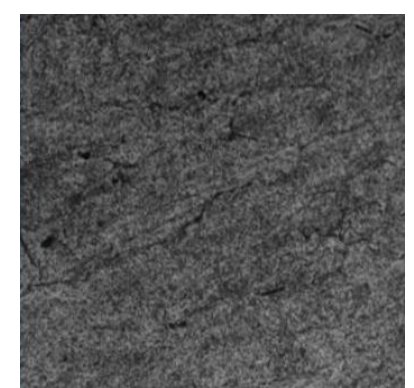

(b) $\mathrm{Al} 6061+2.5 \% \mathrm{ZrO} 2$

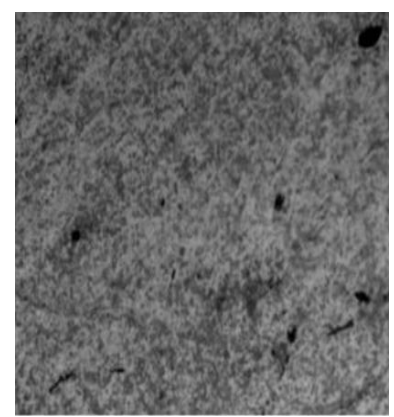

(d) $\mathrm{Al} 6061+2 \% \mathrm{ZrO} 2+1 \% \mathrm{Gr}$ 


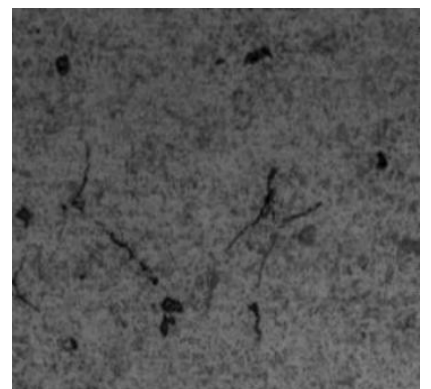

(e) $\mathrm{Al} 6061+4 \% \mathrm{ZrO} 2+1 \% \mathrm{Gr}$

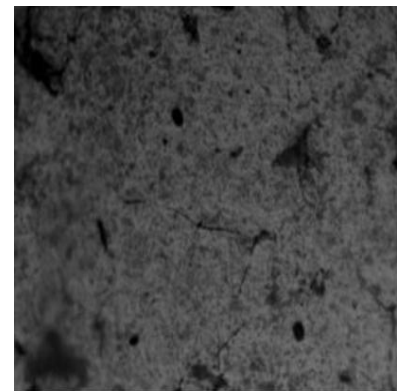

(f) $\mathrm{Al} 6061+6 \% \mathrm{ZrO} 2+1 \% \mathrm{Gr}$
The microstructure study shown in figure 2 clearly indicates the uniform distribution of $\mathrm{ZrO}_{2}$ and graphite particles in a matrix alloy. The porosity in both base alloy and the composite is very less. This Microstructure consists of fine inter-metallic precipitates in a matrix of aluminum solid solution. These precipitates are responsible for creating rough surfaces which resists the wear loss. From figure 2 (f) it can be observed that the excessive addition of reinforcements leads to poor binding strength and increase in porosity due to which the composite may lose its strength.

\subsection{Micro-Hardness Test}

Vickers hardness test also known as micro-hardness test is used for measuring the hardness of the matrix alloy and the composites so prepared. Standard test method IS: 1501-202 (RA 2007) was used for measuring the hardness of the matrix material and hybrid composites. Standard test specimens of diameter $15 \mathrm{~mm}$ and length $15 \mathrm{~mm}$ were used for this purpose. Hardness is considered to be resistance of the material to indentation or penetration. Micro Vickers diamond indenter pyramid was used for penetration using a constant set load. This will enable an indentation on the specimen. The diagonals of the square indentation are measured as Vickers micro indentation value using which micro Vickers hardness value is determined. It has to be noted that lesser penetration means more hardness. The load value of micro Vickers hardness test range from few grams to several kilograms. The maximum load that a micro Vickers hardness test accompanies is $30 \mathrm{~kg}$ 's. It is very important to prepare a smooth material surface for this purpose. This will enable good indentation shape and measurement.

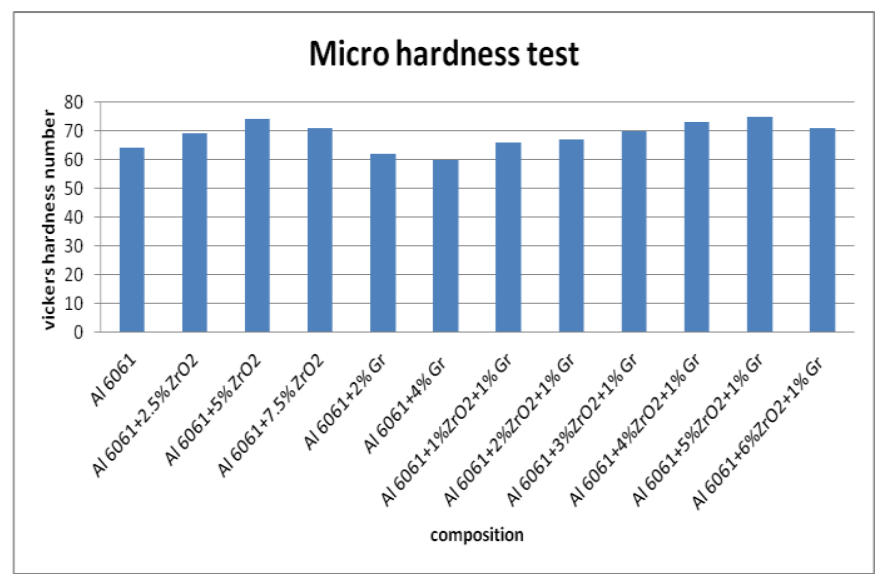

Graph was plotted for the resulted Vickers hardness test values for matrix metal alloy as well as for various compositions. It is seen from the figure 3 that the hardness exhibited by the matrix alloy is less and the hardness keeps on increasing with the increase in $\mathrm{ZrO}_{2}$ reinforcement inclusions. The hardness value decreases with addition of graphite, this may due to low density possessed by the graphite which makes the composite to lose its resistance for the indentation. Fig. 3 also shows the hardness values for various hybrid composite reinforcements. Hardness value decreases beyond 5\% wt percent inclusion of reinforcements this is because of the increased porosity and decreased compactness of the matrix to hold the reinforcements in place.

\subsection{Tensile Test}

Tensile test of the composites was carried on Universal Testing Machine. Tensile test was done to evaluate tensile properties of the composite and these results were compared with the aluminium alloy. Testing system used in this regard is of computerized hydraulic type with load cells in place for measuring the instantaneous load. The equipment is capable of auto plotting the desired graphs. Test specimens made of $10 \mathrm{~mm}$ diameter and $50 \mathrm{~mm}$ gauge length was considered for the experiments. Figure 4 shows the specimens prepared for this purpose. ASTM E8 standard procedure was adapted for conducting the experiments.

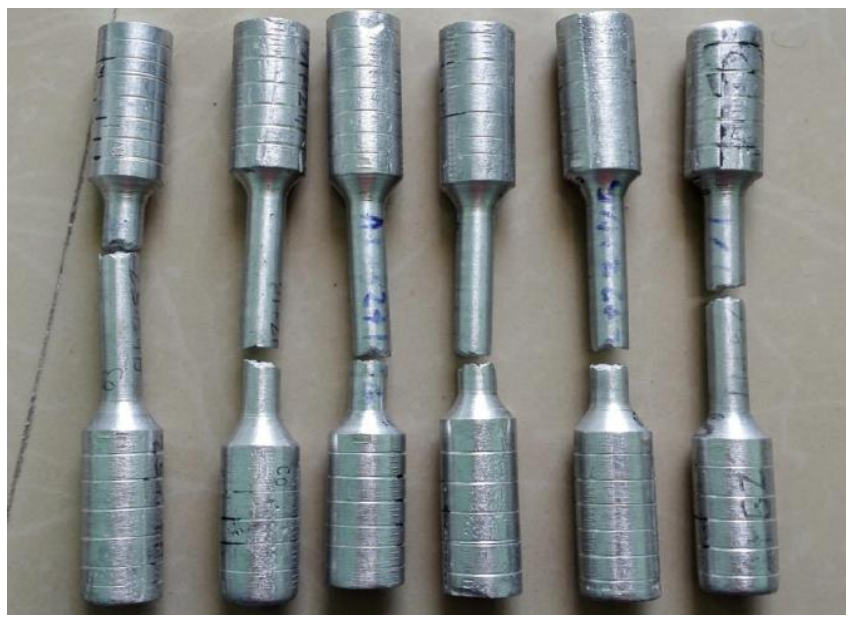

Figure 4. Tensile test specimens.

Fracture load, yield strength, ultimate stress, percentage of elongation and percentage reduction in area for the matrix alloy and various compositions is as shown in the table. It is observed that the fracture load of the matrix alloy increases due to inclusion of $\mathrm{ZrO} 2$ and Gr. This is because Gr softens the material increasing its ductility. Hence, fracture load bearing capacity of the composition increases. This remains same; up to the composition $\mathrm{Al} 17075+2 \% \mathrm{ZrO} 2+1 \% \mathrm{Gr}$. 
Table 3: Tensile test results

\begin{tabular}{|c|c|c|c|c|}
\hline $\begin{array}{l}\text { Material } \\
\text { composition }\end{array}$ & $\begin{array}{l}\text { Break } \\
\text { load in } \\
\mathrm{N}\end{array}$ & $\begin{array}{l}\text { Ultimate } \\
\text { stress in } \\
\text { Mpa }\end{array}$ & $\begin{array}{l}\% \text { of } \\
\text { Elongation }\end{array}$ & $\begin{array}{l}\% \text { of } \\
\text { Reduction }\end{array}$ \\
\hline $\mathrm{Al} 6061$ & 8250 & 112.45 & 4.04 & 5.7 \\
\hline $\begin{array}{l}\mathrm{Al} 6061+2.5 \% \\
\mathrm{ZrO}_{2}\end{array}$ & 6700 & 108.4 & 3.44 & 7.81 \\
\hline $\begin{array}{l}\mathrm{Al} 6061+5 \% \\
\mathrm{ZrO}_{2}\end{array}$ & 5950 & 76.79 & 2.4 & 4.1 \\
\hline $\begin{array}{l}\mathrm{Al} 6061+7.5 \% \\
\mathrm{ZrO}_{2}\end{array}$ & 5800 & 73.6 & 3.3 & 4.9 \\
\hline $\begin{array}{l}\mathrm{Al} 6061+2 \% \\
\mathrm{Gr}\end{array}$ & 9150 & 121.26 & 3.38 & 6.25 \\
\hline $\begin{array}{l}\mathrm{Al} 6061+4 \% \\
\mathrm{Gr}\end{array}$ & 8050 & 110.32 & 3.42 & 3.9 \\
\hline $\begin{array}{l}\mathrm{Al} 6061+1 \% \\
\mathrm{ZrO}_{2}+1 \% \mathrm{Gr}\end{array}$ & 11300 & 142.391 & 6.62 & 11.2 \\
\hline $\begin{array}{l}\mathrm{Al} 6061+2 \% \\
\mathrm{ZrO}_{2}+1 \% \mathrm{Gr}\end{array}$ & 11400 & 130.271 & 5.44 & 7.015 \\
\hline $\begin{array}{l}\mathrm{Al} 6061+3 \% \\
\mathrm{ZrO}_{2}+1 \% \mathrm{Gr}\end{array}$ & 8100 & 101.26 & 3.86 & 5.08 \\
\hline $\begin{array}{l}\mathrm{Al} 6061+4 \% \\
\mathrm{ZrO}_{2}+1 \% \mathrm{Gr}\end{array}$ & 7900 & 99.011 & 3.36 & 4.83 \\
\hline $\begin{array}{l}\mathrm{Al} 6061+5 \% \\
\mathrm{ZrO}_{2}+1 \% \mathrm{Gr}\end{array}$ & 7200 & 90.367 & 2.84 & 4.71 \\
\hline $\begin{array}{l}\mathrm{Al} 6061+6 \% \\
\mathrm{ZrO}_{2}+1 \% \mathrm{Gr}\end{array}$ & 6650 & 82.805 & 2 & 4.697 \\
\hline
\end{tabular}

Fracture reduces with further increase in the hybrid compositions. This is because; further increase in the composition will lead to reduction in ductility of the material. Figure 5 shows ultimate tensile stress has reduced continuously with the increase of reinforcements inclusions. There is a drastic decrease in percentage of elongation and percentage of reductions due to reinforcement inclusions.

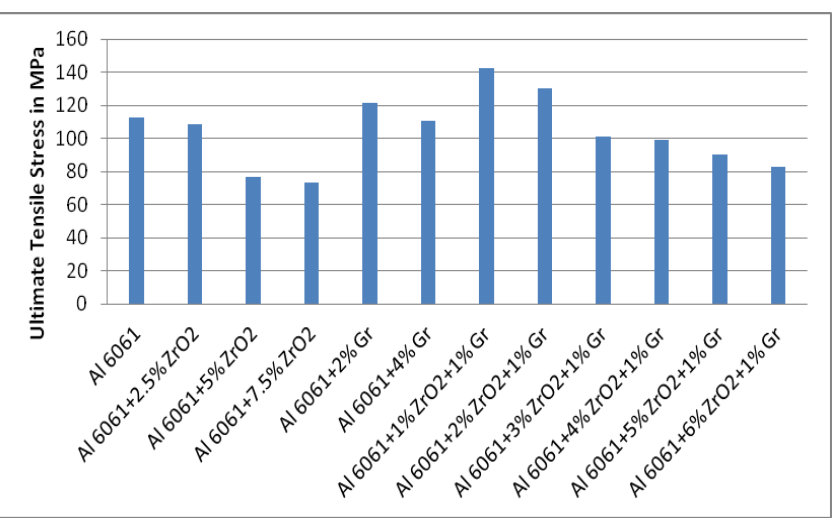

Figure: 5 Ultimate tensile strength $v / s$ material compostion Hence, it is very evident that the inclusion of reinforcements results in increase of hardness and results in decrease of the ductile properties of the material.

\subsection{Impact test}

An important type of loading is dynamic loading in which the load is applied suddenly, as from the impact of moving mass. In the design of many types of structures and machines that must take impact loading, the aim is to provide for the absorption of as much energy as possible through elastic action and then to rely on some kind of damping to dissipate it. In such structures of machines the resilience date derived from static loading may not be adequate. The mechanics of the impact involved not only the stresses but also consideration of energy transfer and energy absorption and dissipation. ASTM E23 standard procedure was adapted to perform the experiment.

It is clearly observed from the above figure 6 . that the impact resistance of Al6061 matrix alloy increases due to less percentage inclusion of reinforcements. However, the impact resistance reduces due to further increase in reinforcements. This is because at lesser percentage inclusion of reinforcement Graphite is predominant which makes the hybrid composite material soft and more ductile leading to high impact resistance.

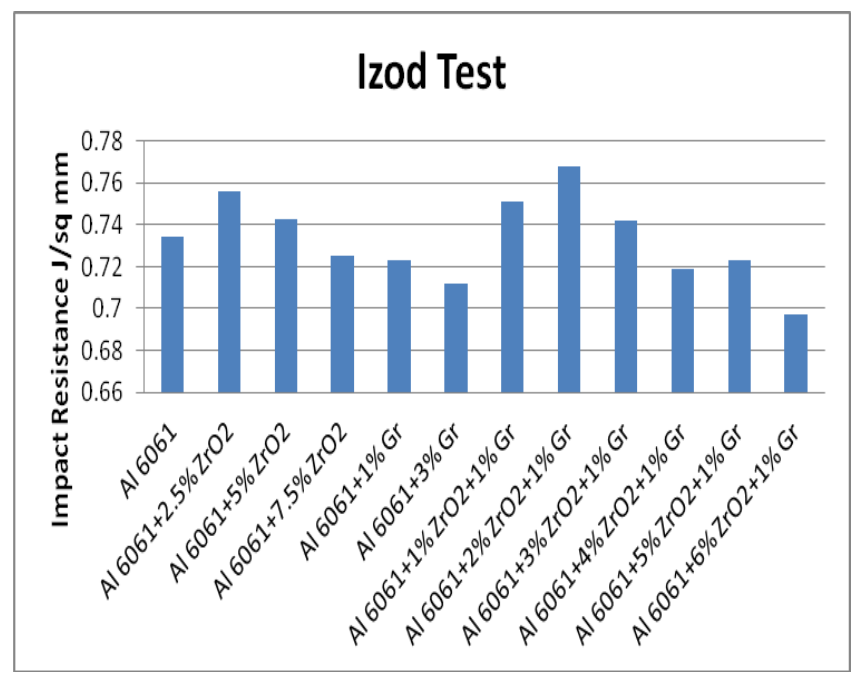

Figure 6. Impact resistance $v / s$ material composition

Further, increase of reinforcements, increases $\mathrm{ZrO} 2$ content which lead to more brittle structure of the material. Hence, more hardness and less impact resistance are observed. It is clearly observed from the graph that the impact resistance of a material increases with the increase of Gr content and reduces with the increase of $\mathrm{ZrO} 2$. Increase of $\mathrm{Gr}$ inclusions more than stipulated limit will make the composite more soft and lead to lesser impact resistance. A clear understanding states that a harder structure of composite is obtained with less percentage inclusion of solid lubricants and more percentage inclusions of $\mathrm{ZrO} 2$.

\section{1 CONCLUSIONS DRAWN}

The following conclusions are drawn from the test results.

- The study reveals that $\mathrm{ZrO}_{2}$ particles increase the hardness of the composite.

- Addition of $2 \%$ (by wt fraction) graphite reinforcement increases the tensile strength of the composite.

- Impact resistance of the composite increase with increase in wt $\%$ of $\mathrm{ZrO}_{2}$ reinforcement

- The tensile strength resistance of the composite decreases with increase by addition of $\mathrm{ZrO}_{2}$ reinforcement 
From the above study we can conclude that reinforcements have significant role in enhancing the properties of particulate reinforced composites up to a certain volume fraction, further addition of reinforcements will lead to decrement in properties compared to base metal.

\subsection{Scope For Future Work}

In this study A16061 based hybrid composites with varying weight percentages of $\mathrm{ZrO}_{2}$ and constant weight percentage inclusion of Gr were considered to improve the mechanical properties of AL6061 based metal matrix alloy. This work can be further processed by enhancing the tribological properties of the composite composition mixture by heat treatment processes. Significant developments have shown that heat treatments processes are carried out to improve mechanical properties such as tensile strength, impact resistance, ductility etc. Heat treatments are also employed to increase the hybrid composite resistance to wear, abrasion and corrosion. Heat treatments may also increase the surface hardness of the composites to minimize the wear between the mating surfaces.

\section{REFERENCES}

[1] Bryan Harris, 'Engineering Composite Materials', The Institute of Materials, London, 1999.

[2] Gururaja M N, A N Hari Rao, 'A Review on Recent Applications and Future Prospectus of Hybrid Composites, International Journal of Soft Computing and Engineering (IJSCE), ISSN: 2231-2307, Volume1, Issue-6, January 2012.

[3] Manoj Singla, D. Deepak Dwived, Lakhvir Singh, Vikas Chawla, 'Development of Aluminium Based Silicon Carbide Particulate Metal Matrix Composite', Journal of Minerals \& Materials Characterization \& Engineering, Vol. 8, No.6, pp 455-467, 2009.

[4] M. A. Baghchesara1, H. Abdizadeh and H. R. Baharvandi, 'Fractography Of Stir Casted $\mathrm{Al}-\mathrm{Zro}_{2}$ Composites', Iranian Journal of Science \& Technology, Transaction B, Engineering, Vol. 33, No. B5, pp 453462, 2009.

[5] Faiz Ahmad, S.H. Jason Lo, Muhammad Aslam, Ahmad Haziq, 'Tribology Behaviour of Alumina Particles Reinforced Aluminium Matrix Composites and Brake Disc Materials'. International Tribology Conference Malaysia 2013.

[6] A.B. Gurcan, T.N. Baker, 'Wear behaviour of AA6061 aluminium alloy and its composites'. Wear 188 (1995) 185-191.

[7] S. V. Prasad, B. D. McConnell, 'Tribology of aluminum metal-matrix composites: lubrication by graphite'. Wear, 149 (1991) 241-253.

[8] L. H. Hihara, R. M. Latanision, 'Residual Microstructural Chloride in Graphite-Aluminum Metal Matrix Composites'. Materials Science and Engineering, A126 (1990) 231-234.

[9] A.M.S. Hamouda, M.S.J. Hashrni, 'Mechanical Properties of Aluminium Metal Matrix Composites Under Impact Loading'. Journal of Materials Processing Technology 56 (1996) 743-756.
[10] Heguo Zhu, CuicuiJar, JinzhuSong, JunZhao, JianliangLi, ZonghanXie, 'High temperature dry sliding friction and wear behavior of aluminum matrix composites (Al3Zrpa-Al2O3)/Al'. Tribology International48(2012)78-86.

[11] S. Sawla, S. Das, 'Combined effect of reinforcement and heat treatment on the two body abrasive wear of aluminum alloy and aluminum particle composites'. Wear, 257 (2004) 555-561.

[12] Yishi Su, Qiubao Ouyang, Wenlong Zhang, Zhiqiang Li, Qiang Guo, Genlian Fan, DiZhang, 'Composite structure modeling and mechanical behavior of particle reinforced metal matrix composites'.Materials Science \& Engineering,A597(2014)359-369. 